\title{
Mechanical and Thermal Properties of the Waste Low and High Density Polyethylene-nanoclay Composites
}

\author{
ARKAN J. HADI ${ }^{1}$, H. K. ABDULKADIR ${ }^{2 *}$, GHASSAN J. HADI ${ }^{3}$, \\ KAMAL BINYUSOH ${ }^{4}$ and SYED FARHAN HASANY ${ }^{5}$ \\ ${ }^{1}$ Chemical Engineering Department, Faculty of Engineering, Soran University, \\ Soran, Erbil Kurdistan Region, Iraq. \\ ${ }^{2}$ Chemical \& Petrochemical Engineering Department, College of Engineering, \\ Anbar University, Ramadi, Iraq. \\ ${ }^{3}$ Al Dour Technical Institution, Technical Education Organization, Tikrit, Salahaldden, Iraq. \\ ${ }^{4}$ Faculty of Chemical and Natural Resources Engineering, Universiti Malaysia Pahang, \\ Lebuhraya Tun Razak, 26300 Gambang, Kuantan, Pahang, Malaysia. \\ ${ }^{5}$ Department of Chemistry NED UET, Karachi, 75950, Pakistan. \\ *Corresponding author E-mai:habdulkadir56@uoanbar.edu.iq \\ http://dx.doi.org/10.13005/ojc/340259 \\ (Received: October 24, 2017; Accepted: January 01, 2018)

\begin{abstract}
In extension with the previous work, recycling of the waste polyolefins by dissolution/ reprecipitation method, has been investigated. The goal of study was to explore the influence of organo-modified/ unmodified sodium montmorillonite clays, on the behaviours of waste polyolefins inclusive low density polyethylene (LDPE) and high density polyethylene (HDPE). 1-5 wt \% of unmodified (MMT) and Organo-modified clay (OMMT) were added to the polyolefins, to prepare polyolefin-clay nanocomposites by melt intercalation method. X-ray diffraction (XRD) and Field Emission Scanning Electron Microscope (FESEM) were used to estimate the dispersion of clay in the polymer matrices and the morphology of nanocomposites. Thermogravimetric analysis (TGA) and Differential Scanning Calorimetry (DSC) were used to analyse the change in the thermic properties of the waste polyolefins nanocomposites. The XRD and FESEM results showed an intercalated structure in the HDPE and LDPE with Organo-clay nanocomposites, whereas no exfoliation was observed with unmodified clay in both waste HDPE and LDPE, respectively. DSC and TGA, showed an improved thermal behaviours in the HDPE/Organo-clay nanocomposites $(3 \mathrm{wt} \%)$ clay loading. Melting temperature and crystallization percentage were observed to increase in 1, 2, and 3 wt\% loadings. In waste LDPE/ clay nanocomposites, no improvement was established in the thermal stability.
\end{abstract}

Keywords: Thermal properties, Nanocomposites, Polyolefins, Unmodified clay, Organo-clay. 


\section{INTRODUCTION}

Polymeric materials are progressing largely in recent and innovative applications, extending between bicycles to aerospace, ware to customer electronics, farming, and sporty industries. Polymeric materials are significant type of material science, which endures to be a developing field in forthcoming decades ${ }^{1-3}$. Recently, the demand of polymeric consumption (mostly plastic), has increased dramatically due to increasing world population and the requirements, respectively ${ }^{4,5}$.

The manufactured amount of plastic rigid wastes escalated in no time, although the growing efforts to minimize, reuse, recycle and recover the wastes are progressive to a higher extent. The increment is predominantly due to extensive plastic applications in the packaging and food industry, and in other everyday goods simply because they do not own any side effects that can be detrimental to human kind ${ }^{6}$.

Montmorillonite is one of the most common smectite, which has wide applications because of its higher cation exchanging and ability of puffiness, rise superficies area, and ensuing powerful adsorptions ${ }^{7}$. There are two normal types of montmorillonite, where sodium montmorillonite exhibited a higher ability of puffiness in water whereas calcium montmorillonite possessed low ability of puffiness.

The capability to interchange cations in the interlayer area and clay particles uniform dispersion regulate the most fascinating behaviours of the substance, that can be employed as a filler for nanocomposites presenting distinctive mechanistic behaviours ${ }^{8,9}$. The advancement in polymer nanocomposites, during the past two decades has further reinforced the manufacturing usage of the polymeric materials.

In specific, polymer-clay nanocomposites have a fabulous region of research catching attention. Different kinds of polymeric matrixes (thermoset, thermoplastics, and rubbers), full of with clays have been investigated. Between the clays, montmorillonite (MMT)-based clays, have been assured to be a effective nano-additives in the polymeric matrixes by displaying better properties (thermic, mechanistic, and optic), at least clay concentrations of between 3-5 wt $\%^{10-13}$.

Material properties description and the paths to find isotactic polypropylene (iPP) based nanocomposites with organo-modified montmorillonite (o-MMT), recently revised $\mathrm{in}^{14}$. Hasegawa et al., ${ }^{15}$ and Kawasumi et al., ${ }^{16}$ are reviewed polyolefin and polypropylene/clay mixture depend on adjusted polyolefins and organophilic clay. There are many researcher also worked on the polyethylene (PE) with o-MMT as nanocomposite using different ways for instance PE polymerization in the existence of layered silicate ${ }^{17-19}$ and $^{20,21}$ are used the enforcement of polyethylene-grafted-maleic anhydride (PE-g-MA) as a matrices.

Trading and lab. prepared straight low density PE (LLDPE), PE-g-MA grades were used by Wang et al.,22, where melt mixing method were used to prepare silicate nanocomposites, by lab. prepared LLDPE-g-MA and LLDPE reacted with PE-g-MA, respectively. The application of LLDPE-g-MA, as a compatibilizer for HDPE/o-MMT system was studied by ${ }^{23}$. Low density polyethylene (LDPE), a extensively utilized packaging matter, sounds to be especially striking for nanocomposite production, commonly because of the supposed advancement of obstacle characteristics. Nevertheless, the details concerning this nanocomposites, with PE-g-MA, as a compatibilizer, are uncommon ${ }^{24}$.

The influences of clay exfoliation in LDPE based nanocomposite ${ }^{24}$ were worst the HDPE based system, due to further difficult permeation of unlinear LDPE polymer molecules into clay galleries. Olewnik et al., ${ }^{25}$, studied the creation of polyolefins/adjusted montmorillonite nanocomposites about 1.5-5 wt\% clay adjusted with 4, 4' methylenebisaniline, with an emphases on the thermal and structural properties of generated nanocomposites. The clay content effect on the structural behaviour of polypropylene (PP) and high density polyethylene (HDPE) composites, also were revised by ${ }^{26}$.

Drozdov et al., ${ }^{27}$, studied a comparison of the result in the polymer/clay composite properties 
for many researcher. It was reported, "There are many experimental studies regarding the morphology and mechanical properties of inserted and exfoliated nanocomposites with HDPE matrixes. It has been reported that support of HDPE with MMT clay layers consequences in (i) an expansion in the Young's modulus, and (ii) a reduction in extending at break. The same consequences have been revealed in experiments on other polymer-clay nanocomposites, as well as on particulate microcomposites, the abovementioned results may be considered as accurate".

Based on the previously reported research and our studies on the recycling of the polyolefin ${ }^{28-32}$. The following study enlightens the synthesis of waste polyolefin/ Organ-modified and unmodified sodium montmorillonite nanocomposites, by melt interaction method and exploring the effect of clay content on the waste LDPE and HDPE structural, thermal and mechanical properties. The characterization behaviour of the resulting polyolefin/clay nanocomposites are studied by XRD and FESEM, respectively. Mechanical (Tensile and nanoindentation) and the thermal behaviours were analysed by using Instron Universal testing machine, TGA, and DSC. The properties of the new waste polyolefin/clay nanocomposites were later compared with the original waste polymer nanocomposites, compatibly.

\section{EXPERIMENTAL}

\section{Materials}

The waste polyolefin material was collected from $\mathrm{h}$ trash, waste LDPE was collected from generally used bags name for an easy treatment $(B)$, density $0.927 \mathrm{~g} / \mathrm{cm}^{3}$, melt flow index $0.841 \mathrm{~g} / 10$ minutes. The waste HDPE was collected from empty chemical containers in the lab. (D), density $0.962 \mathrm{~g} / \mathrm{cm}^{3}$, melt flow index $0.252 \mathrm{~g} / 10$ minutes. The unmodified sodium montmorillonite and organo-modefied clay (Cloisite 20A), were purchased from Southern Clay Products Inc., USA.

\section{Method preparation of the nanocomposite}

Firstly, the polymer samples were prepared by washing and cleaning up with tap water and cutting them into smaller pieces, by using plastic crusher machine to the size $2-4 \mathrm{~cm}$, respectively. The clay was added (1, 2, 3 and 5) wt $\%$, to the waste polymer. Secondly, the clay and the waste polyolefin samples were blended in a Kitchen Aid type mixer, for about 15-30 minutes. The blended mixture was oven dried at $60 \mathrm{pC}$, for overnight period. The mixture was then fed to an extruder for $20 \mathrm{~min}$. as blending time. Twin-screw extruder (EuroLab $16 \mathrm{XL}$ ), co-rotating, screw diameter $16 \mathrm{~mm}, \mathrm{~L} / \mathrm{D}=25$ was used for the nanocomposites preparation. Temperature for the extruder were set as $150 \mathrm{pC}$, whereas $190 \mathrm{pC}$ was set at the hopper. The screw speed was fixed at $80 \mathrm{rpm}$ for all the samples.

\section{Characterization}

X-ray diffraction (XRD) patterns between $3^{\circ}-80^{\circ}$ were obtained with an X-ray diffractometer (Rigaku Mini Flexll, Japan) using CuKa filter radiation $(\lambda=\mid 0.15406 \mathrm{~nm})$, at $30 \mathrm{kV}$ and $15 \mathrm{~mA}$. The morphology of the nanocomposites was investigated by field emission scanning electron microscopy (FESEM; JEOL EVO-50, Japan). The breaking ends of samples were mounted on aluminium stubs and spotter coated with a thin layer of gold to prevent electrostatic charged through out testing.

Differential Scanning Calorimetry, DSC Q1000 (V9.6, Build 290) from TA instrument was used to determine melting temperature, enthalpy of fusion $\left(\Delta \mathrm{H}_{\mathrm{f}}^{\mathrm{exp}}\right)$ and crystallinity $(\% \mathrm{C})$. The testing are accomplished depend on ASTM D3418-03, with temperature perior $20-300{ }^{\circ} \mathrm{C}$ and a scan rate of $10^{\circ} \mathrm{C} / \mathrm{min}$. in nitrogen atmosphere. Thermal stability for the samples before and after fabrication were determined by thermogravimetric analyser (TGA) through heating at the rate of $20^{\circ} \mathrm{C} / \mathrm{min}$. from $20-800{ }^{\circ} \mathrm{C}$, in dry $\mathrm{N}_{2} .25-30 \mathrm{mg}$ sample will prepared for the testing.

The testing were accomplished employing a Universal V4.5A, TA Apparatuses. The Universal Testing Machine Shimadzu AG-X, was used to measure the tensile mechanical properties. The testing was performed according to the standard ASTM D638-03 (type I) with speeds of the testing were $5 \mathrm{~mm} /$ minutes. The sample was prepared using a hydraulic thermo press under the following conditions of: temperature $\left(190{ }^{\circ} \mathrm{C}\right)$, pressure (10MPa), time of heating (15 min.). The 
testing had done after $48-72 \mathrm{~h}$ in room temperature and $55-60 \%$ humidity.

\section{RESULTS AND DISCUSSIONS}

\section{X-Ray diffraction}

X-ray diffractograms of waste LDPE and HDPE and respective nanocomposites are presented in Fig. 1and 2, respectively. The XRD patterns showed two distinct 110 at and 200 reflection peaks. The 110 and the 200 peaks are noticed at $21.76^{\circ}$ and at $24.04^{\circ}$, respectively for $\mathrm{HDPE} /$ clay nanocomposites, and at $21.64^{\circ}$ and at $23.94^{\circ}$, respectively for LDPE/clay nanocomposites, with no obvious difference between them.

In comparison with the HDPE, LDPE/ Organo-modified clay and non-modified clay systems, the PE/Organoclay system has a better dispersion of Organoclay in the matrix, which may be the result of the strong interaction between organic modified clay molecules and the particular silicate layer. In weight percent clay addition, the peaks remarkably lowered, revealing proper exfoliation of clay in the polyolefin matrices, in spite of the exfoliation is lower in HDPE/unmodified clay and LDPE/clay nanocomposites than in HDPE/Organo-modified clay. The results are consistent with the previously reported results ${ }^{21,22,33}$

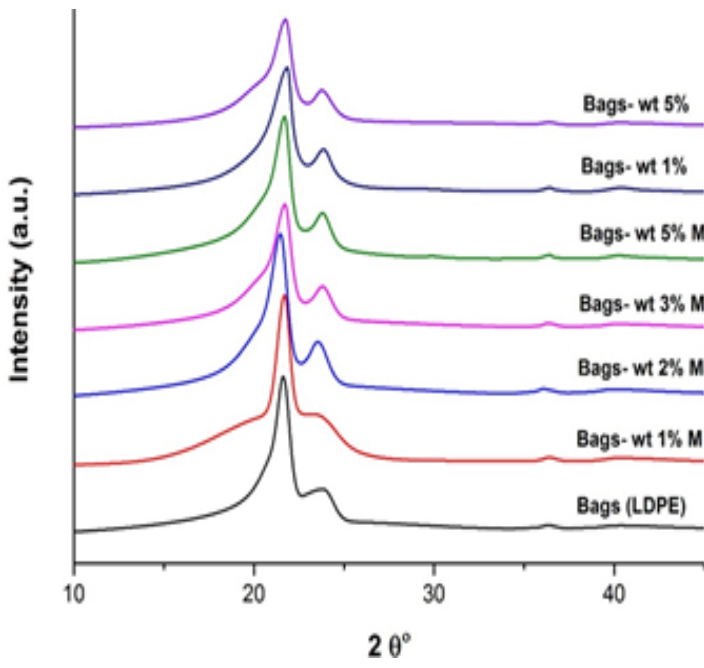

Fig. 1. X-ray diffraction curves of waste LDPE (Bags) and waste LDPE /clay nanocomposites, where $M$ is mean the modified clay

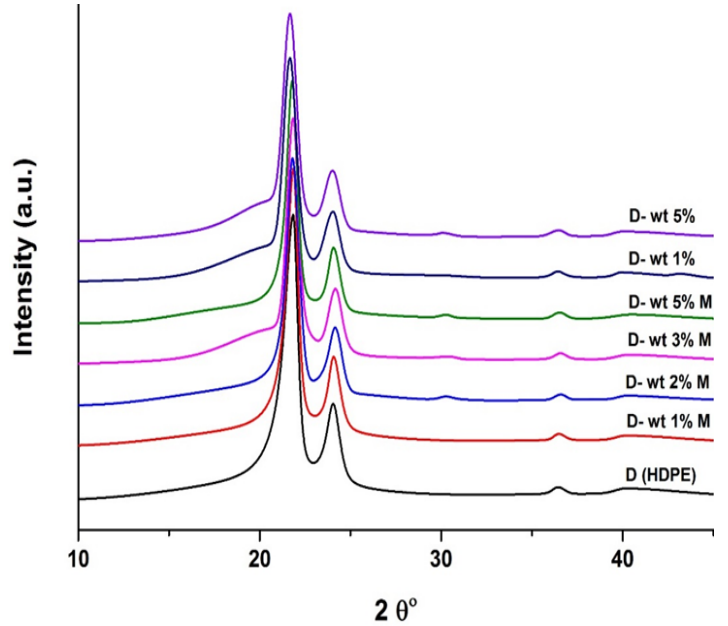

Fig. 2. X-ray diffraction curves of waste HDPE, Chemical container (D) and waste HDPE /clay nanocomposites, where $M$ is mean the modified clay

\section{FESEM studies}

FESEM testings as shown in Fig. 3 and 4 showed a good correlation with X-RD results, indicated the intercalation of $2 \mathrm{wt} \%$ modified and unmodified clay into the waste LDPE and HDPE, respectively. The exfoliation phenomenon of insertion and accumulation is complicated to study from FESEM definitively, that can be simply indicated with the XRD studies. Fig. 3 b showed a good compounding between the organo-modified clay, on the other hand in figure $3 \mathrm{c}$ small exfoliation can be observed. In the case of waste LDPE the exfoliation in the two types of clay was very slight. ${ }^{34,35}$

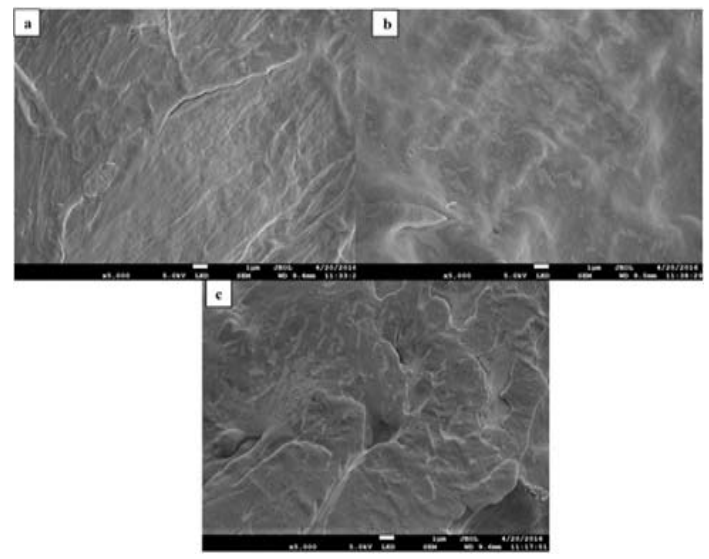

Fig. 3. The FESEM images of the surfaces of a) pristine waste LDPE and the b) nanocomposites at 2 wt \% organo-modified (Cloisite 20A) clay and c) 2 wt \% unmodified clay 


\section{Differential scanning calorimetry}

Thermal properties (fusion behaviour melting point and crystallinity), of the waste polyolefin and nanocomposites of variable clay concentration were analysed by using DSC technique (Table 1). The percent crystallinity (\%C) is then determined using the following equation:

$\% \mathrm{C}=\left[\Delta \mathrm{H}_{\mathrm{f}}^{\exp } / \Delta \mathrm{H}_{\mathrm{f}}^{0}\right] \times 100 \%$

where, $\Delta \mathrm{H}^{\exp }{ }_{\mathrm{f}}$ is the experimental enthalpy of fusion of the specimen tested. $\Delta \mathrm{H}_{\mathrm{f}}^{\exp }$ is calculated by measuring the area under the thermogram peak in terms of $\mathrm{J} / \mathrm{g}$, while $\Delta \mathrm{H}_{\mathrm{f}}^{0}$ is a standard value and represents the enthalpy of fusion if the polymer were $100 \%$ crystalline, it has been taken to be 293J/ $\mathrm{g}$ for PE (LDPE and HDPE) ${ }^{36,37}$. MMT, in addition has minimal effects on the melting temperature of both the waste HDPE and LDPE, respectively. The melting temperature of waste HDPE/OMMT nanocomposite with 1 and 5 wt\% OMMT, slightly increased to $137.33^{\circ} \mathrm{C}$, when compared with $136.2^{\circ} \mathrm{C}$, for a neat waste HDPE. In waste LDPE nanocomposites, no temperature change was observed by OMMT addition. DSC results showed that little quantity of OMMT in the HDPE matrix produced a slight increment in the melting temperature. The phenomenon may have occurred because of the effective nucleation influences of the silicate strata/ tactoids ${ }^{38,39}$.

Table 1: Melting temperature Tm, Heat of melting $\mathrm{Hm}$, and degree of crystallinity $\mathrm{C}$, of nanocomposites as a function of MMT and OMMT component

\begin{tabular}{|c|c|c|c|c|}
\hline \multirow[t]{2}{*}{ Sample } & \multicolumn{3}{|c|}{$\begin{array}{c}\text { Temperatur } /{ }^{\circ} \mathrm{C} \\
\text { at mass loss }\end{array}$} & \multirow{2}{*}{$\begin{array}{r}\text { Residue at } \\
600{ }^{\circ} \mathrm{C} \%\end{array}$} \\
\hline & $5 \%$ & $10 \%$ & $50 \%$ & \\
\hline D & 430 & 443 & 470 & 0.64 \\
\hline D $1 \% M$ & 431 & 448 & 472 & 1.06 \\
\hline D $2 \% M$ & 436 & 450 & 473 & 1.24 \\
\hline D $3 \% M$ & 427 & 441 & 462 & 1.05 \\
\hline D $5 \% M$ & 427 & 442 & 464 & 2.51 \\
\hline D $1 \%$ & 426 & 445 & 473 & 2.46 \\
\hline D $5 \%$ & 428 & 443 & 471 & 3.63 \\
\hline B & 413 & 428 & 461 & 0.62 \\
\hline B $1 \% M$ & 426 & 438 & 463 & 1.30 \\
\hline B $2 \% M$ & 430 & 440 & 458 & 1.73 \\
\hline B $3 \% M$ & 429 & 440 & 459 & 1.70 \\
\hline B $5 \% M$ & 428 & 440 & 457 & 2.17 \\
\hline B $1 \%$ & 417 & 432 & 464 & 1.83 \\
\hline B $5 \%$ & 414 & 429 & 462 & 3.91 \\
\hline
\end{tabular}

The heat of fusion $\mathrm{Hm}$, for waste HDPE/OMMT nanocomposites increased significantly, especially at lower loadings (1-3 wt\%), and showed a little decrease in further clay addition. however still it is higher than the pure waste HDPE. In MMT addition $\mathrm{Hm}$ was increased very slightly in 1 and 2 wt\% clay concentrations, while decreased in comparison with the pure waste HDPE, with higher clay concentrations. Different results were observed for LDPE/clay nanocomposites, where only for $1 \mathrm{wt} \%$ OMMT concentration, the heat of fusion increased very slightly, while decreased was observed for all the samples. It was also observed to be lower than $\mathrm{Hm}$ value for neat waste LDPE, with the MMT addition.

The phenomenon may be produced by the stoppage of crystalline outgrowth, instigated by the clay layers, distributed in an uneven arrangement in the nanocomposite, as observed in some of the thermal microscopy researches ${ }^{40}$.

\section{Thermogravimetric analysis}

The material thermal degradation of the samples were studied by TGA analysis. The outset temperature of the degeneration are the important parameters, that is metric as that is indicated $5 \%-10 \%$ weight loss of the specimen, the middle-period of the thermal degeneration, and the final calculation of thermic degeneration is the portion of substance that is non-volatile at $873 \mathrm{pK}$, famous as charcoal, respectively ${ }^{41}$.

Figures 5 and 6 depicts the TGA curves for neat LDPE, HDPE and LDEP, HDPE /clay nanocomposites containing 1,2,3, $5 \mathrm{wt} \%$ of OMMT, and $1,5 \mathrm{wt} \%$ of MMT, respectively. The temperature weight loss 5, 10 and $50 \%$ and the residue are presented at $600{ }^{\circ} \mathrm{C}$ in Table 2. LDPE /OMMT nanocomposites at 1-3 wt\% clay showed increasing thermic constancy as equated to organized waste LDPE. The beginning of thermic constancy is distinguished by the temperatures at 5\%,10\% weight loss. The LDPE/OMMT nanocomposites showed significantly enhanced initial thermal stability at $5 \%$ and $10 \%$ weight loss, when compared with the pure waste LDPE. The LDPE/OMMT nanocomposite with 3 wt\% clay, display the critical initial thermic constancy. When the OMMT components is raised up more than 
$3 \mathrm{wt} \%$, the beginning of thermic constancy decreased even in 4 and 5 wt $\%$ still higher than pristine LDPE, but it is less than that with 3 wt $\%$ content. For $50 \%$ weight loss the thermal stability has not had much change.

At comparatively lesser OMMT component, the first thermic constancy rises with OMMT component. The results in LDPE/MMT nanocomposites were different, the temperatures at $5 \%, 10 \%$ and $50 \%$ mass loss were not found changed when compared with pure LDPE.The reason behind that may be because of the accumulations of clay, that have low influence in stopping heat in comparison with the MMT sheets/tactoids, rising with clay component ${ }^{39}$.

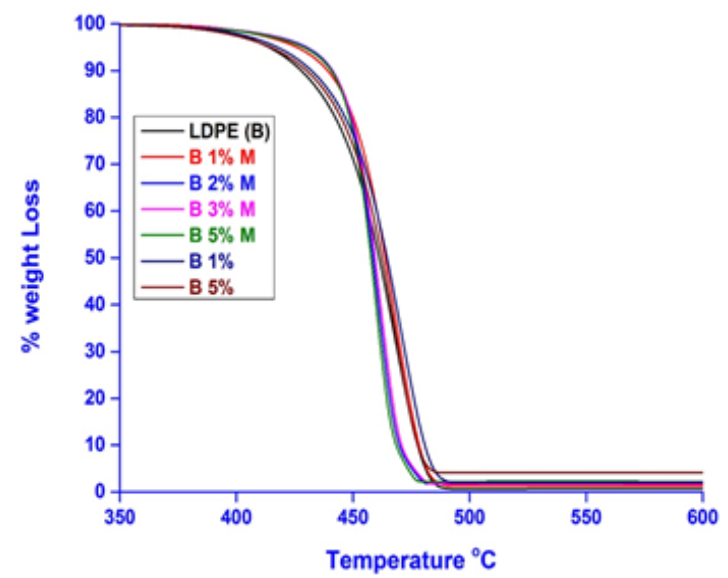

Fig. 5. TGA analysis for waste LDPE (B) and LDPE/clay nanocomposites

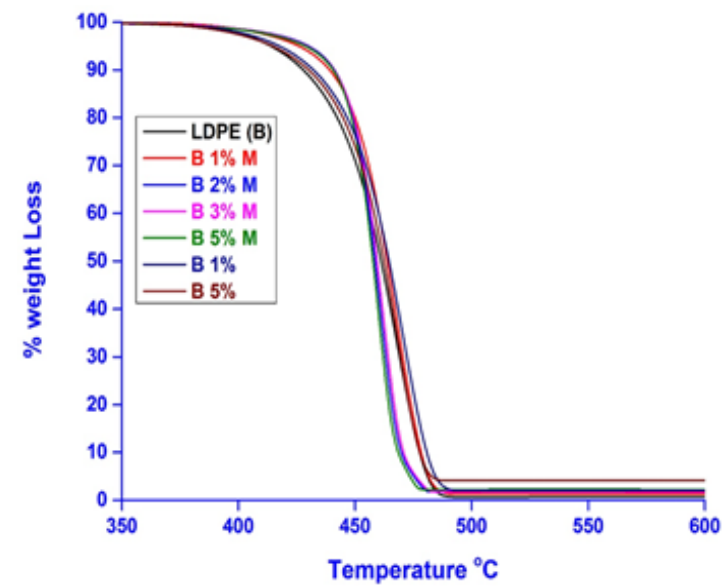

Fig. 6. TGA analysis for waste HDPE (B) and HDPE/clay nanocomposites
Table 2: TGA data for waste LDPE, HDPE and their nanocomposites under nitrogen flow

\begin{tabular}{llccc}
\hline Sample & \multicolumn{3}{c}{ Temperature / ${ }^{\circ} \mathrm{C}$ at } & $\begin{array}{c}\text { Residue at } \\
\text { mass loss }\end{array}$ \\
& $5 \%$ & $10 \%$ & $50 \%$ & \\
& & & & \\
\hline & 430 & 443 & 470 & 0.64 \\
D & 431 & 448 & 472 & 1.06 \\
D 1\% M & 436 & 450 & 473 & 1.24 \\
D 2\% M & 437 & 1.05 \\
D 3\% M & 427 & 441 & 462 & 2.51 \\
D 5\% M & 427 & 442 & 464 & 2.46 \\
D 1\% & 426 & 445 & 473 & 3.63 \\
D 5\% & 428 & 443 & 471 & 0.62 \\
B & 413 & 428 & 461 & 1.30 \\
B 1\% M & 426 & 438 & 463 & 1.73 \\
B 2\% M & 430 & 440 & 458 & 1.70 \\
B 3\% M & 429 & 440 & 459 & 2.17 \\
B 5\% M & 428 & 440 & 457 & 1.83 \\
B 1\% & 417 & 432 & 464 & 3.91 \\
B 5 \% & 414 & 429 & 462 & \\
\hline
\end{tabular}

On the other hand in case of HDPE/clay nanocomposites, we observed almost the same results with a slight deference. The higher thermal stability was observed for the samples $1 \%$ and $2 \%$ wt OMMT content only, at the temperatures at 5\%, 10\% and $50 \%$ weight loss has slightly decreased in first thermic constancy if the clay content increased more than $2 \%$ wt. in the mid-point at $50 \%$ weight loss of $3 \%$ and $5 \%$ wt OMMT were considerably decreased to $462 \mathrm{pC}$ and $464{ }^{\circ} \mathrm{C}$ compared with $470{ }^{\circ} \mathrm{C}$ for the pure waste HDPE. The temperature at 5\%, 10\% and $50 \%$ weight loss of HDPE/MMT nanocomposites were very slightly changed when compared with the pure waste HDPE. That is for may be for the same reason mention in LDPE/clay nanocomposites ${ }^{39}$

\section{Mechanical characteristics}

The mechanistic characteristics of the matrix LDPE and HDPE/clay nanocomposites were measured and compared with those of the pure waste and recycled LDPE and HDPE by dissolution/ reprecipitation method. Fig. 5 shows the elastic modulus, tensile stress at maximum load strain at break and tensile stress at yield.

The elastic modulus plots of samples are shown in Fig. 5 a. The measured modulus of pure LDPE and HDPE were found 150 and $462 \mathrm{Mpa}$ respectively, which increased significantly when 
modified clay (OMMT) was added from 1-3 wt\%, and were decreased at 5 wt $\%$ OMMT, even the non-modified clay (MMT), addition decreased the modulus. The highest modulus were observed as $207 \mathrm{MPa}$ in LDPE/ nanocomposites, with an increase of $38 \%$ in relation with the pure waste LDPE and the highest modulus was found as $496 \mathrm{MPa}$ in HDPE/ nanocomposites, 7.4\% higher
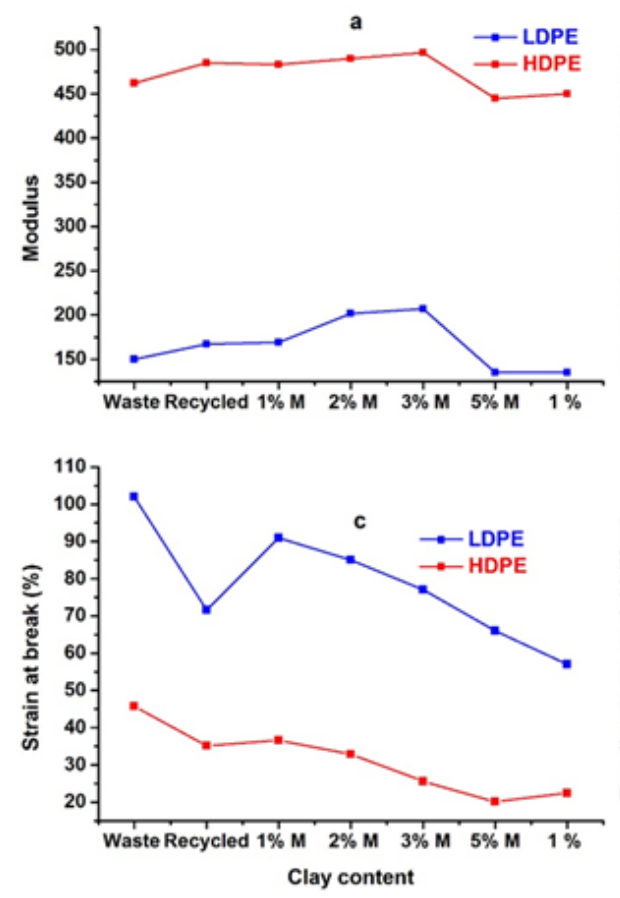

Fig. 7. Effect of clay loading on tensile properties of LDPE and HDPE/ clay nanocomposites

On the other hand, the other three mechanical properties, tensile stress at maximum load, strain at break and tensile stress at yield are showed in Fig. 5 b, c and d respectively. All the following properties were observed to decrease with the clay addition. A higher decrease in the behaviours were observed with the MMT contents addition, in comparison to the OMMT content studies. The considerable reduction in the mechanical properties, at clay loadings is because of the regularly sparse MMT tactoids with the inserted structures ${ }^{37}$.

\section{CONCLUSION}

The waste polyolefin (LDPE and HDPE) / clay (unmodified and organo-modified), nanocomposites were fabricated by employing the melt intercalation method. The physicochemical to the pure waste HDPE. The elastic modulus increased with the addition of org-clay in low contents of $1-3 \mathrm{wt} \%$. The OMMT when dispersed in the polyolefin matrix at a nanometre scale, a part of the OMMT gets inserted by polyolefin chains. This may seize the segmental motion of polyolefin macromolecules. As a result, the modulus of the PP nanocomposites increased with the OMMT loading ${ }^{39,42}$.
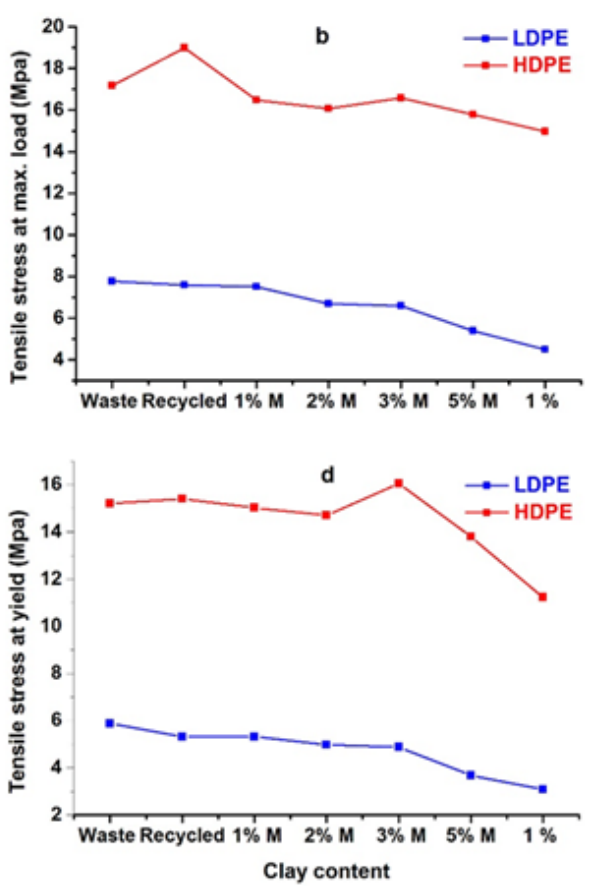

effects of the two types of clay on the structure and properties were also calculated. XRD and FESEM results, exhibited a considerable effect of OMMT due to the exfoliation and interaction of OMMT within the polymer matrix, while there is no exfoliation and intercalation was observed in polymeric composite of MMT.

The DSC results showed that in almost all the samples the melting temperature remained the same with no major alterations. The enthalpy of fusion was increased in nanocomposites at low OMMT content (1-3 wt\%), in comparison with the pure waste polyolefin, whereas the best behaviour was presented by $3 \mathrm{wt} \%$. Same results were observed in the thermal behaviour of the nanocomposites, where enhancement in behaviours were observed at low OMMT content. The highest elastic modulus in the LDPE 
nanocomposites, was increased up to $34 \%$, in relation with the pure waste LDPE, whereas increase of $7.4 \%$, was calculated in HDPE nanocomposites. Tensile stress at maximum load, strain at break and tensile stress at yield were slightly decreased in the low OMMT clay content. Additional clay contents, resulted in a decrease in the mechanical properties of nanocomposites. However, it is concluded from the study that the recycling of the waste polymer using dissolution/ reprecipitation method, showed a better reinforcement of the waste polyolefin by nanocomposites fabrication, in melt interaction method.

\section{ACKNOWLEDGEMENT}

The work was supported by the University of Malaysia, Pahang (Grant No. RDU 150398).

\section{REFERENCES}

1. Kim, Y.K.; Kwon, H.; Choi, W.J.; Woo, C.S.; Park, H.S. Environmental considerations of plastic behaviors for automobile applications. Procedia Engineering., 2011, 10, 1029-34.

2. Gurunathan, T.; Rao, C.R.; Narayan, R.; Raju, K.V. Polyurethane conductive blends and composites: synthesis and applications perspective. Journal of Materials Science., 2013, 48(1), 67-80.

3. Szleifer, I.; Yerushalmi-Rozen, R. Polymers and carbon nanotubes-dimensionality, interactions and nanotechnology. Polymer., 2005, 46(19), 7803-18.

4. Williamson; Recycling of Polymers. Personal communication Shrewsbury, Plastics Consultancy Network, 1995. [Online]. Available: http://www.pcn.org.

5. Curlee, T.R.; Das, S. Plastic waste: management, control, recycling, and disposal. Noyes Data Corporation, 1991, 201.

6. PlasticsEurope, Plastics Europe, 2015. [Online]. Available: www.plasticseurope.org.

7. Xi, Y.; Frost, R.L.; He, H. Modification of the surfaces of Wyoming montmorillonite by the cationic surfactants alkyl trimethyl, dialkyl dimethyl, and trialkyl methyl ammonium bromides. Journal of Colloid and Interface Science., 2007, 305(1), 150-8.

8. Kozak, M.; Domka, L. Adsorption of the quaternary ammonium salts on montmorillonite. Journal of Physics and Chemistry of Solids., 2004, 65(2), 441-5.

9. Roelofs, J.C.; Berben, P.H. Preparation and performance of synthetic organoclays. Applied clay science., 2006, 33(1), 13-20.

10. Xu, B.; Zheng, Q.; Song, Y.; Shangguan, Y. Calculating barrier properties of polymer/clay nanocomposites: effects of clay layers. Polymer. 2006, 47(8), 2904-10.

11. Xu, S.; Tangpong, X.W. Tribological behavior of polyethylene-based nanocomposites. Journal of Materials Science., 2013, 48(2), 578-97.

12. Gawad, A.A.; Esawi, A.M.; Ramadan, A.R. Structure and properties of nylon 6-clay nanocomposites: effect of temperature and reprocessing. Journal of materials science., 2010, 45(24), 6677-84.

13. Manias, E.; Touny, A.; Wu, L.; Strawhecker, K.; Lu, B.; Chung, T.C. Polypropylene/ montmorillonite nanocomposites. Review of the synthetic routes and materials properties. Chemistry of Materials., 2001, 13(10), 3516-23.

14. Hasegawa, N.; Okamoto, H.; Kawasumi, M.; Kato, M.; Tsukigase, A.; Usuki, A. Polyolefinclay hybrids based on modified polyolefins and organophilic clay. Macromolecular Materials and Engineering., 2000, 280(1), 76-9.

15. Kawasumi, M.; Hasegawa, N.; Kato, M.; Usuki,A.; Okada, A. Preparation and Mechanical Properties of PolypropyleneClay Hybrids, Macromolecules., 1997, 30, 6333-6338.

16. Heinemann, J.; Reichert, P.; Thomann, R.; Mulhaupt,R. Polyolefin nanocomposites formed by melt compounding and transition metal catalyzed ethene homo- and copolymerization in the presence of layered silicates, Macromol. Rapid Commun., 1999, 20, 423-430.

17. Jin, Y.H.; Park, H.J.; Im, S.S.; Kwak, S.Y.; Kwak, S. Polyethylene/clay nanocomposite by in-situ exfoliation of montmorillonite during Ziegler-Natta polymerization of ethylene. 
Macromolecular rapid communications. 2002, 23(2), 135-40.

18. Alexandre, M.; Dubois, P.; Sun, T.; Garces, JM.; Jérôme, R. Polyethylene-layered silicate nanocomposites prepared by the polymerization-filling technique: synthesis and mechanical properties. Polymer., 2002, 43(8), 2123-32.

19. Gopakumar, T.G.; Lee, J.A.; Kontopoulou, M.; Parent, JS. Influence of clay exfoliation on the physical properties of montmorillonite/ polyethylene composites. Polymer., 2002, 43(20), 5483-91.

20. Koo, C.M.; Ham, H.T.; Kim, S.O.; Wang, K.H.; Chung, I.J.; Kim, D.C.; Zin, W.C. Morphology evolution and anisotropic phase formation of the maleated polyethylene-layered silicate nanocomposites. Macromolecules., 2002, 35(13), 5116-22.

21. Wang, K.H.; Choi, M.H.; Koo, C.M.; Choi, Y.S.; Chung, I.J. Synthesis and characterization of maleated polyethylene/clay nanocomposites. Polymer., 2001, 42(24), 9819-26.

22. Kato, M.; Okamoto, H.; Hasegawa, N. Tsukigase, A.; Usuki, A. Preparation and properties of polyethyleneclay hybrids. Polymer Engineering \& Science. 2003 , 43(6), 1312-6.

23. Liang, G.; Xu, J.; Bao, S.; Xu, W. Polyethylene/maleic anhydride grafted polyethylene/organicmontmorillonite nanocomposites. I. Preparation, microstructure, and mechanical properties. Journal of Applied Polymer Science. 2004 , 91(6), 3974-80.

24. Olewnik, E.; Garman, K.; Czerwiñski, W. Thermal properties of new composites based on nanoclay, polyethylene and polypropylene. Journal of Thermal Analysis and Calorimetry. 2010 , 101(1), 323-9.

25. Mohan, T.P.; Kanny, K. Melt blend studies of nanoclay-filled polypropylene (PP)-highdensity polyethylene (HDPE) composites. Journal of materials science., $2013,48(23)$, 8292-301.

26. Drozdov, A.D.; Christiansenb, J.deC. Cyclic viscoplasticity of high-density polyethylene/ montmorillonite clay nanocomposite. European polymer journal., 2007, 43(1), 10-25.

27. Hadi, A.J.; Najmuldeen, G.F.; Ahmed, I. Potential solvent for reconditioning polyolefin waste materials. 2012, 585-591.

28. Jasim, A.; Faisal, G. Reconditioning Process Of Waste Low Density Polyethylene Using
New Technique, 2012, 1(8), 400-410.

29. Hadi, A.J.; Najmuldeen, G.F.; Ahmed, I. Polyolefins waste materials reconditioning using dissolution/reprecipitation method. APCBEE Procedia. 2012, 3, 281-6.

30. Hadi, A. J.; Najmuldeen, G. F.; Kamal,Y. Recycling of polyolefins waste materials by dissolution/reprecipitation technique using an organic solvent, Energy Educ. Sci. Technol., 2013, 30(2).

31. Hadi, A.J.; Najmuldeen, G.F.; Yusoh, K.B. Dissolution/reprecipitation technique for waste polyolefin recycling using new pure and blend organic solvents. Journal of Polymer Engineering., 2013, 33(5), 471-81.

32. Wang, K.H.; Chung, I.J.; Jang, M.C.; Keum, J.K.; Song, H.H. Deformation behavior of polyethylene/silicate nanocomposites as studied by real-time wide-angle X-ray scattering. Macromolecules. 2002, 35(14), 5529-35.

33. Pradhan, K.C.; Nayak, P.L. Synthesis and characterization of polyurethane nanocomposite from castor oil-hexamethylene diisocyanate (HMDI). Adv Appl Sci Res. 2012, 3(5), 3045-52.

34. TN 48, Polymer Heats of Fusion, TA Instruments.

35. Wunderlich, B. Thermal Analysis, Acad. Press, 1990, 417-431.

36. Araújo, E.; Barbosa, R.; Morais, C.; Soledade, L.; Souza, A.; Vieira, M. Effects of organoclays on the thermal processing of pe/clay nanocomposites. Journal of thermal analysis and calorimetry., 2007, 90(3), 841-8.

37. Ding, C.; Jia, D.; He, H.; Guo, B.; Hong, H. How organo-montmorillonite truly affects the structure and properties of polypropylene. Polymer Testing. 2005 , 24(1), 94-100.

38. Burgaz, E. Poly (ethylene-oxide)/clay/silica nanocomposites: Morphology and thermomechanical properties. Polymer. 2011, 52(22), 5118-26.

39. Chigwada, G.; Wang, D.; Wilkie, C.A. Polystyrene nanocomposites based on quinolinium and pyridinium surfactants. Polymer Degradation and Stability., 2006 , 91(4), 848-55.

40. Durmuํ, A.; Woo, M.; Kagöz, A.; Macosko, C.W.; Tsapatsis, M. Intercalated linear low density polyethylene (LLDPE)/clay nanocomposites prepared with oxidized polyethylene as a new type compatibilizer: structural, mechanical and barrier properties. European Polymer Journal., 2007, 43(9), 3737-49. 